\title{
O Conceito de Má consciênCia na Filosofia de Nietzsche Versus o Conceito de Superego na Metapsicologia de Freud
}

\author{
[The Concept of Bad Consciousness in Nietzsche's Philosophy versus the Concept \\ of Superego in Freud's Metapsychology]
}

\author{
Alessandra Uchôa Sisnando * \\ Italo de Azevedo Gomes ** \\ Universidade Federal Rural de Pernambuco, Brasil
}

RESUMo: O presente trabalho tem o escopo de realizar uma comparação dos raciocínios que levaram à cunhagem de dois conceitos próximos: a Má Consciência, conforme descrita na obra Genealogia da Moral, de Friedrich Nietzsche; e o Supereu de Sigmund Freud, levando em conta sua obra Mal-Estar da Civilização (Cultura). Um dos elementos de aproximação entre os dois autores é o seguinte raciocínio: por conta de uma instância exterior a si mesmo, o homem desenvolveria uma tendência interior à autocontenção e à autoflagelação. Esta tendência seria uma propriedade adoecedora, contra a qual Nietzsche e Freud se sublevam. Em Nietzsche, esta autocensura é a má consciência: um sentimento de culpa que se abate sobre os homens pelo fato deles quererem exercer a sua força. $\mathrm{O}$ prazer instintual, animalesco e humano, uma vez amordaçado pelas leis da comunidade, pela responsabilidade, termina resultando na má consciência. Em Freud, o sujeito deve, em função do benefício da vida comunitária, moderar suas ambições de fruição do prazer. Ou seja, uma contenção que inicialmente era exterior e social, é internalizada e passa a compor a estrutura da mente do sujeito em questão.

Palanras-Chave: Nietzsche; Freud; MáConsciência; Superego; Recalque
ABSTRACT: This paper aims to compare the reasoning that led to the coining of two close concepts: Bad Consciousness, as described in Friedrich Nietzsche's On the Genealogy of Morality; and Sigmund Freud's Superego, taking into account his work Civilization and Its Discontents (Culture). One of the elements of approximation between the two authors is the following reasoning: on account of an instance outside himself, man would develop an inner tendency toward self-restraint and selfflagellation. This tendency would be a sickening property, which Nietzsche and Freud repel. In Nietzsche, this self-censorship is the bad conscience: a sense of guilt that comes upon men because they want to exert their strength. Instinctual, animalistic, human pleasure, once gagged by the laws of the community, by responsibility, ends up in bad conscience. In Freud, the subject must, by virtue of the benefit of community life, moderate his ambitions for the enjoyment of pleasure. That is, a restraint that was initially external and social, is internalized and becomes part of the mind structure of the subject in question.

KEYwORDS: Nietzsche; Freud; Bad Conscience; Superego; Repression

* Doutora em Filosofia pela Universidade Federal de Pernambuco. Professora efetiva de Filosofia Política da Universidade Federal Rural de Pernambuco - UFRPE. Aleuchoa7@gmail.com. ** Pós-Graduado em Ensino da Filosofia pela FAINTVISA - Espaço Contemporâneo. Graduado em Psicologia pela Universidade Católica de Pernambuco (UNICAP).italodag@hotmail.com. 


\section{INTRODUÇÃo}

presente artigo tem o escopo de esclarecer convergências e divergências nos raciocínios que levaram à cunhagem de dois conceitos próximos: a MáConsciência, conforme construída na obra Genealogia da Moral, de Friedrich Nietzsche; e o Superego de Sigmund Freud, levando em conta sua obra Mal Estar da Civilização ${ }^{1}$.

Um dos elementos de aproximação entre os dois autores é o seguinte raciocínio: por conta de uma instância exterior a si mesmo, o homem desenvolveria uma tendência interior à autocontenção e à autoflagelação. Esta tendência seria um fator de adoecimento, contra a qual Nietzsche e Freud se sublevam, através de diferentes formulações, com diferentes alcances e diferentes esperanças.

\section{A Má ConsciênCia}

Nietzsche define má consciência em um aforismo famoso na segunda dissertação de sua Genealogia da Moral, o aforismo 16:

Todos os instintos que não se descarregam para fora voltam-se para dentro - isto é o que chamo de interiorização do homem: é assim que no homem cresce o que depois se denomina sua "alma".

\section{(...)}

Aqueles terríveis bastiões com que a organização do Estado se protegia dos velhos instintos de liberdade - os castigos, sobretudo, estão entre esses bastiões fizeram com que todos aqueles instintos do homem selvagem, livre e errante se voltassem para trás, contra o homem mesmo. A hostilidade, a crueldade, o prazer na perseguição, no assalto, na mudança, na destruição - tudo isso se voltando contra os possuidores de tais instintos: esta é a origem da má consciência.

Com ela, porém, foi introduzida a maior e mais sinistra doença, da qual até hoje não se curou a humanidade, o sofrimento do homem com o homem, consigo: como resultado de uma violenta separação do seu passado animal, como que um salto e uma queda em novas situações e condições de existência, resultado de uma declaração de guerra aos velhos instintos nos quais até então se baseava sua força, seu prazer e o temor que inspirava. (NIETZSCHE, 1887/2018, p.67).

Deste trecho, alguns elementos merecem explicitação. Em primeiro lugar, a existência de um homem animalesco, cheio do que Nietzsche chamou de "velhos instintos de liberdade". Como a Genealogia da Moral é uma tentativa de tratar os assuntos da moral não como essenciais ou a priori, mas como dinâmicos e mutantes ao longo da história, seu autor buscou inspiração nas teorias evolucionistas da história natural quando tinha que falar do bicho-homem². Não poucas comparações foram feitas entre este ponto do pensamento de Nietzsche e a ideia de Estado de Natureza em Hobbes $^{3}$. O fato é que o pensador da má consciência considerava que "do mais alto ponto de vista biológico, os estados de direito não podem ser senão estados de exceção" (NIETZSCHE, 1887/2018, p.60).

Apesar disso, há inúmeras vantagens em fazer parte de uma coletividade 
(NIETZSCHE, 1887/2018, p.55), e é inegável que em algum momento a convivência comunitária se impôs como modo de vida da espécie humana. No trecho a seguir, Nietzsche compara o que sucedeu ao ser humano, ao tornar-se gregário, com o que aconteceu em outros processos evolucionários no mundo animal:

O mesmo que deve ter sucedido aos animais aquáticos, quando foram obrigados a tornarem-se animais terrestres ou perecer, ocorreu a esses semianimais adaptados de modo feliz à natureza selvagem, à vida errante, à guerra, à aventura subitamente seus instintos ficaram sem valor e 'suspensos'. (NIETZSCHE, 1887/2018, p.67)

Assim, ironicamente esse animal feliz e livre, guiado pelo instinto, acaba sendo posteriormente moldado pela própria natureza (NIETZSCHE, 1887/2018, p.43) para a capacidade de fazer promessas: objetivo que "traz consigo, como condição e preparação, a tarefa mais imediata de tornar o homem até certo ponto necessário, uniforme, igual entre os iguais, constante e, portanto, confiável" (NIETZSCHE, $1887 / 2018$, p.44). Isto se faz através do castigo, da violência, da punição àqueles que se sublevarem às regras da comunidade. Aliás, a própria comunidade humana é firmada pela violência - é ela que cria as regras do convívio social, a serem exercida por uns sobre outros. Por isso, conforme citado acima, o protótipo de Estado se defende dos instintos de liberdade através do direito de punir instituído.

Segundo Nietzsche, a gênese do conceito moral de culpa ocorre a partir do conceito de dívida. Ocorre que nas sociedades ditas primitivas, uma dívida que não pudesse ser paga com valores ou bens, deveria ser paga concedendo-se ao credor o prazer de torturar e de exercer sua força sobre o devedor. $\mathrm{O}$ autor enfatiza o prazer de causar dor, relembrando as penas físicas que eram a regra até recentemente no direito penal.

Em seguida, desenvolve-se uma noção de dívida em relação aos antepassados, pois se considera que a comunidade não seria possível sem eles. Por esta lógica, passa a ser necessário pagar esta dívida com rituais de sacrifício, oferecendo aos espíritos ancestrais o sofrimento dos vivos em troca de bênçãos e proteção místicas. À medida que passa o tempo e a aura mística dos ídolos aumenta, o sentimento de dívida também aumenta, culminando na criação de Deus e na internalização da dívida na forma moralizante da culpa.

Este é o primeiro sentido da má consciência: um evento evolutivo da espécie humana que decorre diretamente da sujeição do indivíduo à lei comunitária e da supressão de seus instintos de violência, de forma que estes são direcionados para o próprio indivíduo, resultando no sentimento de culpa.

O segundo sentido da má consciência é aquele que pode ser considerado sinônimo de doença em Nietzsche: uma cultura que, baseando-se na culpa, adota uma postura de negação da vida.

Esta culpa, esta má consciência, é a matéria prima dos sacerdotes, os homens que obtêm seu poder e sua influência da crença religiosa difundida. Destes, o autor da Genealogia da Moral diz o seguinte:

O grande estratagema de que se utilizou o sacerdote ascético para fazer ressoar na alma humana toda espécie de música pungente e arrebatada consistiu - todos sabem - em aproveitar-se do sentimento de culpa. (NIETZSCHE, 1887/2018, p.120)

A moral sacerdotal é, para Nietzsche, uma moral do ressentimento. Os sacerdotes ressentem-se dos fortes, considerando imorais suas atividades, como a 
guerra, por exemplo. Ressentem-se dos belos e condenam a vaidade. E assim sucessivamente para cada um dos valores próprios da vitalidade e da saúde.

O povo que melhor desenvolveu esta moral sacerdotal foi exatamente o povo judeu. Convencidos de que eram escolhidos por Deus, os judeus foram contraditoriamente e repetidamente derrotados no campo de batalha; foram escravizados e expulsos de suas terras por povos que naquele momento eram mais poderosos militarmente e, assim, identificaram o mal com a força e o bem com o ponto de vista do fraco e oprimido.

A popularização do Cristianismo - que é uma reforma da religião judaica trouxe esta decadência aos povos gregos em um processo que foi nomeado por Nietzsche de transvaloração dos valores. Isto significa que ao longo dos anos, a moral judaico-cristã logrou êxito em alterar os valores gregos clássicos, contaminando-os e submetendo os fortes a uma autocensura moral.

Esta autocensura é, também, a má consciência: um sentimento de culpa que se abate sobre os homens pelo fato deles quererem exercer a sua força.

\section{O SUPEREGO}

Veja-se, de início, o que diz Freud sobre seu próprio conceito:

A agressividade é introjetada, internalizada, mas é propriamente mandada de volta para o lugar de onde veio, ou seja, é dirigida contra o próprio Eu. Lá é acolhida por uma parte do Eu que se contrapõe ao resto como Super-eu, e que, como 'consciência', dispõe-se a exercer contra o Eu a mesma severa agressividade que o Eu gostaria de satisfazer em outros indivíduos. À tensão entre o rigoroso Super-eu e o Eu a ele submetido chamamos consciência de culpa; ela se manifesta como necessidade de punição. A civilização controla então o perigoso prazer em agredir que tem o indivíduo, ao enfraquecê-lo, desarmá-lo e fazer com que seja vigiado por uma instância no seu interior, como por uma guarnição numa cidade conquistada. (FREUD, 1930/2011, p. 69)

Segundo Freud, a dimensão da mente humana que corresponde à consciência de si - o ego, em linguagem psicanalítica - passa, a partir do nascimento, por um processo de desenvolvimento. Ao nascer, a criança não distingue seu mundo interior do mundo exterior, bem como não se sente um ser separado da mãe. O ego do recém-nascido não foi ainda estruturado, de forma que é possível imaginar esta mente arcaica como parte de um grande mecanismo que envolve situações desprazerosas (como a fome, por exemplo), depois o choro e, em seguida, o seio materno (ou os cuidados maternos).

Sendo puro desejo, o bebê funciona movido por pulsões. Freud constata que no início da vida, os seres humanos adotam rapidamente o que chamou de princípio do prazer: agem sempre no sentido de maximizar o prazer e evitar a dor. O ego, portanto, reuniria no mundo interno as fontes de prazer e exteriorizaria os estímulos dolorosos. No entanto, há fontes de desprazer que provém "de dentro", do mundo interno, da própria psique humana - ou do seu próprio corpo, como a fome, por exemplo. Existem, concomitantemente, fontes de prazer exteriores, que fogem ao controle do bebê e que, por isso, podem ficar indisponíveis por algum tempo. Dessa forma, o desenvolvimento normal do ego consiste em afastar fontes exteriores de desprazer, delimitando-se em relação ao que é externo; e também em afastar fontes interiores de desprazer, relegandoas às cavernas escuras da mente através do que foi chamado por Freud de recalque.

A seguinte frase pertence a Freud: "Como se vê, é simplesmente o programa do princípio do prazer que estabelece a finalidade da vida” (FREUD, 1930/2011, p. 20). 
Isto nada mais é do que uma forma de Hedonismo. O psicanalista justifica esta opção, inicialmente, pela observação empírica dos bebês humanos, mas depois estende esta concepção para os adultos.

Pode-se dizer que a sustentação do argumento hedonista tem um viés duplo: em primeiro lugar, conta com a necessária delimitação de objeto de conhecimento científico. "Delimita-se" o ser humano em torno de seu inconsciente; assim, uma investigação científica (psicanalítica) do ser humano se torna uma investigação do seu inconsciente - exatamente onde moram pulsões recalcadas (contraparte psíquica dos instintos). ${ }^{4}$

Em segundo lugar, a negação da metafísica, traduzida na proposta de uma vida sem sentido a priori, gera um vazio a ser preenchido pela vaga ideia de felicidade. Se o sujeito é seu inconsciente, sua felicidade não poderia ter melhor definição do que a simples satisfação do desejo imediato.

Freud arquiteta a partir daí uma economia libidinal. Trata-se de uma compilação de possíveis estratégias para satisfazer o máximo possível os desejos instintuais, incorrendo no menor risco possível de sofrimento (que, aqui, foi identificado com o desprazer).

Assim, há a estratégia de buscar o máximo de prazer a todo custo, que traz consigo o risco de desprazer igualmente intenso; há a estratégia de isolar-se do convívio e da alteridade para evitar o desprazer oriundo de outras pessoas, alcançando-se assim a "felicidade da quietude". Outro caminho proposto por Freud - este bem moderno - é a sujeição da natureza (pela técnica científica) às necessidades humanas para obtenção do bem comum, ampliando-se o espectro e a intensidade de prazer disponíveis.

A intoxicação aparece como um método de ampliação da felicidade bastante difundido. Aqui, o autor refere-se ao álcool e outras diversas drogas que foram usadas em todos os tempos pelos indivíduos para obtenção de prazer (FREUD, 1930/2011, p. 21-22).

De toda forma, um raciocínio "econômico", de custo benefício, guiaria as ações do homem em direção à felicidade. Diante daquilo que não pode controlar, em termos de ampliação do prazer, o ser humano adotaria uma postura de redução do desprazer, acomodando-se em suas expectativas de fruição. Neste raciocínio, pode-se dizer que em algum nível, todo homem modera suas reivindicações de felicidade e se contenta com o que tem.

Caso as estratégias de felicidade não obtenham o êxito esperado, o sujeito pode adoecer. É a fuga neurótica: o sofrimento psíquico se manifesta das mais variadas formas para atestar sua própria existência, que é sempre negada pelo recalque. Este seria o último caso, e o pior (embora o cientista não deva fazer juízos de valor, e embora Freud não o faça, aqui, abre-se esta possibilidade).

Considerando a importância dada ao princípio do prazer pela metapsicologia freudiana, um dos objetivos mais profundamente inscritos na humanidade passa a ser evitar o desprazer; dessa forma, faz sentido que boa parte dos esforços e da inteligência humanos tenham sido empregados para reduzir os riscos em que incorrem os indivíduos, só pelo simples fato de estarem vivos; afinal de contas, basta estar vivo para correr o risco da morte.

A maior invenção humana neste sentido é a civilização. Todos os primatas vivem em bando, mas os seres humanos inventaram uma forma de se relacionar que permite ao indivíduo ter uma expectativa razoável do que pode acontecer com ele no futuro - e dos riscos que ele pode correr. Em geral, a vida na civilização é mais segura do que a vida na natureza selvagem.

Viver em civilização faz parte do conjunto de estratégias que a criatura humana 
possui para maximizar seu prazer e minimizar seu desprazer. Por isso mesmo é que despertou o interesse de Freud o simples fato de que, entre as fontes de sofrimento que ele pôde enumerar, o oriundo do contato com outras pessoas (contato este que é fundamental na civilização) foi considerado o mais difícil de lidar. Outros sofrimentos, como o poder superior da natureza ou a fragilidade e declínio dos corpos foram considerados sofrimentos inescapáveis, diante dos quais o indivíduo deve se curvar. Por outro lado, a dor causada pelas inadequações da sociedade é sempre vista como inadmissível.

Como é possível que as regras que a própria humanidade construiu para si massacrem tanto alguns de seus membros? O fato é que muitas vezes, em muitas épocas, muitas pessoas desejaram poder viver separados da civilização.

O Mal-Estar na Civilização é uma obra em que Freud procura definir o liame social entre as pessoas como um corolário da atração sexual (amor) e da necessidade de ajuda mútua (FREUD, 1930/2011, p. 46-48). No entanto, o objetivo principal do texto é realçar o mal-estar que muitos dos membros de qualquer comunidade sentem por estarem inseridos nela. Afinal de contas, "a civilização é construída sobre a renúncia instintual. (...) É algo que tem seus perigos” (FREUD, 1930/2011, p. 43).

Neste ponto, entra a influência do pensamento político de Hobbes ${ }^{5}$ : em um estado pré-civilizatório (estado de natureza), a ameaça de morte é presumivelmente gigantesca; porém, as possibilidades de satisfação do prazer são limitadas somente pela força do sujeito. Ao fundar a civilização, o ser humano teve que abrir mão de todas as formas de satisfação que foram, pelo direito, consideradas ilícitas. Novamente, o sujeito deve, em função do benefício da vida comunitária, contentar-se com o pouco que tem e moderar suas ambições de fruição do prazer.

Diante disto, sempre que a vida civilizada parece exigir mais do indivíduo do que o benefício que traz, surge a vontade de romper com esta vida. Freud identifica dois momentos em que isto parece ter acontecido: o primeiro, quando do contato dos europeus com os índios americanos, que pareciam bem mais felizes que seus "visitantes", a despeito de sua aparente incivilidade. O segundo, mais recente, ocorreria no momento em que o próprio Freud revela a seus contemporâneos o recalque: a vida em sociedade exige tal repressão de instintos e pulsões que leva grande número de membros da civilização ao adoecimento neurótico ${ }^{6}$.

Aparentemente, há semelhantes mecanismos em atuação em todos os momentos de grande mudança social e cultural. Diz Freud: "Um fator assim, hostil à civilização, já devia estar presente na vitória do cristianismo sobre as religiões pagãs. Estava ligado à depreciação da vida terrena, efetuada pela doutrina cristã” (FREUD, 1930/2011, p. 31).

\section{Nietzsche E Freud}

Neste ponto, Freud denuncia seu parentesco com Nietzsche: utiliza a palavra "vida", usada também pelo genealogista da moral, e trata do mesmo momento histórico em que este afirma ter havido a transvaloração dos valores ${ }^{7}$. No mais, ambos vão de encontro aos discursos metafísicos e religiosos, abrindo mão da figura de um criador divino e buscando explicações processuais para o fenômeno da culpa. Terminam por proporcionar uma visão mais sóbria do lugar do homem na natureza, o que os leva a investigar para onde vão os instintos que humanos e animais compartilham.

Para concluir, vale a pena pontuar que Nietzsche e Freud, além das contribuições similares, possuem entre si diferenças bastante prolíficas. Nietzsche se propunha a fazer uma filosofia nova. Freud, uma ciência nova. Nietzsche expunha especulações e 
ironizava a busca da verdade, enquanto Freud não hesitava em repetir que sua teoria tinha fundamentos empíricos.

Há, ainda, uma diferença de estilo fundamental entre os dois: Freud seguiria a tendência de descrever os elementos psíquicos com que se deparava como instâncias, partes constitutivas da mente, níveis de consciência ou mesmo locus psíquicos das pulsões. Se ele realmente pensava assim, é questionável; mas o fato é que o pai da psicanálise foi chamado de estruturalista por comentadores.

Nietzsche, ao contrário, preconiza uma mente muito mais dinâmica, baseado em uma definição do homem como vontade de potência, que opõe-se a outras potências em um jogo de forças fluido, mutável e instável.

Enfim, chegamos ao nosso objetivo central no texto: a consonância entre a máconsciência e o conceito de superego, que tem origem na cena edipiana, na castração simbólica efetuada pela figura (ou modo de tratamento, ou função) tradicionalmente chamada de Pai. Ou seja, uma contenção que inicialmente era exterior e social, é internalizada e passa a compor a estrutura da mente do sujeito em questão.

Tanto a má-consciência em Nietzsche como o superego freudiano funcionam como instâncias resultantes de pressões exercidas pela sociedade e suas demandas. As duas são responsáveis pelo enorme sentimento de culpa que o sujeito sente ao romper, ou mesmo ao discordar das regras e ditames sociais.

Essa culpa represada ou recalcada, para usar um termo freudiano, é causadora, para o filósofo, de um adoecimento moral, que conduziria a uma moral dos fracos, a uma sociedade permeada por um discurso doentio de fraqueza, submissão e escravidão, enquanto que para o pai da psicanálise temos, de forma semelhante, uma sociedade adoecida pela renúncia de instintos e pulsões constitutivos da natureza humana.

Além de claramente concordarem que a má-consciência e o superego possuem fundamentos nas relações humanas, os dois pensadores concordam com o desastre causado pela repressão dos instintos humanos. Mas, é importante salientar que Freud, ao contrário de Nietzsche, vê que esse recalque é fundamental para a constituição social e, por isso, concorda que a investigação inconsciente é libertadora na medida em que torna consciente ao indivíduo seus entraves e limitações, sem, no entanto, propor um rompimento radical com a moralidade estabelecida, tal como Nietzsche esboça e deseja na Genealogia da Moral.

Freud parece entender, ao contrário de Nietzsche, que esse grau de repressão é necessário não somente como um meio de construção social, mas, sobretudo como possibilidade de construção do sujeito, pois o superego é a introjeção da lei, que em última instância é a garantia da sanidade mental. Ao passo que Nietzsche entende que a má-consciência é uma espécie de tragédia para o desenvolvimento da vida saudável dos seres humanos.

Podemos concluir dizendo que levando-se em conta as divergências quanto ao argumento final na utilização da teoria, o filósofo encontra paralelo no psicanalista no que se refere ao seu objetivo precípuo, que sempre foi a criação de uma sociedade menos reprimida, menos neurótica, mais saudável. Que o estudo das semelhanças e diferenças entre os dois possa contribuir com este objetivo.

\section{REFERÊNCIAS}

DINIZ, Almachio. O Super-Homem (O fundamento evolucionista do übermensch de Frederich Nietzsche). Cadernos Nietzsche, São Paulo, volume 36, número 2, p. 123-142, Dez. 2015.

FREUD, Sigmund. O Mal-Estar na Civilização (tradução Paulo César de Souza). $1^{\text {a }}$ Edição. São 
Paulo: Penguin Classics Companhia das Letras, 2011. 96 páginas.

GARCIA-ROZA, Luiz Alfredo. Freud e o Inconsciente. 24a Edição. Rio de Janeiro: Zahar, 2009. 240 páginas.

GONÇALVES, Luiz Felipe Xavier. Genealogia do Estado e do Direito em Nietzsche. 20-Fev2019. 125 f. Dissertação (Mestrado) - Curso de Filosofia, Departamento Filosofia, Universidade Federal de Pernambuco, Recife, 2019.

ITAPARICA, André Luis Mota. "Darwin e Nietzsche: natureza e moralidade". In: BARRANECHEA, Miguel Angel de; FEITOSA, Charles; PINHEIRO, Paulo; SUAREZ, Rosana. Nietzsche e as ciências. $1^{\mathrm{a}}$ Edição. Rio de Janeiro: 7 Letras, 2011. 360 páginas.

NIETZSCHE, Friedrich. Genealogia da moral: Uma Polêmica (tradução de Paulo César de Souza). $1^{\text {a }}$ Edição. São Paulo: Companhia das Letras, 2009. 162 páginas.

\section{Notas}

1 Optou-se, neste artigo, por utilizar a tradução mais difundida, embora o superego seja traduzido hodiernamente por supereu, e o título da obra seja mais bem traduzido por Mal Estar da Cultura.

2 Sobre a relação de Nietzsche com o evolucionismo, ver:

ITAPARICA, André Luis Mota "Darwin e Nietzsche: natureza e moralidade". In: Barrenechea, M. A., Feitosa, C., Pinheiro, P., Suarez, S. (Org.). Nietzsche e as ciências. Rio de Janeiro: 7Letras, 2011, pp. 60-70.

DINIZ, Almachio. O Super-Homem (O fundamento evolucionista do übermensch de Frederich Nietzsche). Cadernos Nietzsche, São Paulo, volume 36, número 2, p. 123-142, Dez. 2015.

3 Sobre a relação de Nietzsche com Hobbes e o Estado de Natureza, ver:

GONÇALVES, Luiz Felipe Xavier. Genealogia do Estado e do Direito em Nietzsche. 20-Fev2019. 125 f. Dissertação (Mestrado) - Curso de Filosofia, Departamento Filosofia, Universidade Federal de Pernambuco, Recife, 2019.

4 Segundo Garcia-Roza, "a diferença fundamental entre a pulsão (Trieb) e o instinto (Instinkt) é que este último, além de designar um comportamento hereditariamente fixado, possui um objeto específico, enquanto a pulsão não implica nem comportamento pré-formado, nem objeto específico. É exatamente a variação quanto ao objetivo e ao objeto que se vai constituir num dos pontos centrais da teoria pulsional." GARCIA-ROZA, Luiz Alfredo. Freud e o Inconsciente. 24a ed. Rio de Janeiro: Zahar Ed., 2009, p. 115-116.

5 Pode-se discutir se esta influência se deu diretamente pela leitura de Hobbes por Freud ou se aconteceu através do próprio Nietzsche ou, ainda, por outras fontes.

6 Embora todas as sociedades tenham este condão de supressão dos instintos, é sabido que a sociedade da virada do século XIX para o século XX foi uma das mais repressoras de que se tem notícia; muitas das liberações conquistadas no pós-guerra (movimento hippie, maio de 68 e outras) podem ter sido, de alguma forma, reações a esta repressão da época "vitoriana". Assim, a Viena dos anos 1890 certamente não deve ter sido muito vantajosa em termos de economia libidinal; sabe-se que deu muito material de trabalho e pesquisa a Freud: um grande número de pacientes histéricas.

7 O próprio Nietzsche explica o que é a transvaloração dos valores: "Nada do que na terra se fez contra 'os nobres', 'os poderosos', 'os senhores', 'os donos do poder', é remotamente comparável ao que os judeus contra eles fizeram; os judeus, aquele povo de sacerdotes que soube desforrar-se de seus inimigos e conquistadores apenas através de uma radical tresvaloração dos valores deles (...). Foram os judeus que, com apavorante coerência, (...) se apegaram a esta inversão, a saber, 'os miseráveis somente são os bons, apenas os pobres, impotentes, baixos são bons, os sofredores, necessitados, feios, doentes são os únicos beatos, os únicos abençoados, unicamente para eles há bem-aventurança - mas vocês, nobres e poderosos, vocês serão por toda a eternidade os maus, os cruéis, os lascivos, os insaciáveis, os ímpios, serão também eternamente os desventurados, malditos e danados!...." NIETZSCHE, Friedrich. Genealogia da moral: Uma Polêmica. Trad: Paulo César de Souza. - São Paulo: Companhia das Letras, 2009. I dissertação, §7, p. 23. 